\title{
Justification of Agrotechnical and Operational and Technological Indicators of the Combined Software of Working Bodies
}

\author{
F. G. Huseynov \\ National Academy of Sciences, Azerbaijan Republic Institute of Soil Science and Aqrochemistry, str, M.Rahim 5, Baku AZ1073, \\ Azerbaijan Republic.
}

\begin{abstract}
How to cite this paper: F. G. Huseynov. (2021) Justification of Agrotechnical and Operational and Technological Indicators of the Combined Software of Working Bodies. International Journal of Food Science and Agriculture, 5(3), 519-523. DOI: $10.26855 /$ ijfsa.2021.09.023
\end{abstract}

Received: July 16, 2021

Accepted: August 12, 2021

Published: September 6, 2021

*Corresponding author: F. G. Huseynov, National Academy of Sciences, Azerbaijan Republic Institute of Soil Science and Aqrochemistry, str, M.Rahim 5, Baku AZ1073, Azerbaijan Republic.

Email: tatjana.koka@hotmail.com

\begin{abstract}
The design of the small semicircle for the softener was developed to protect the soil from erosion during soil cultivation. In inter-row cultivated soils, in orchards, vineyards and nurseries, it performs layer-by-layer softening and semi-loosening, deep pillow cultivation by combing out rhubarb and aloe vera residues and mulching plant residues in the upper layers of the crop. The technological process of a two-layer semicircle by layers is theoretically substantiated, analytical dependences of the main structural parameters of a hemisphere are derived. The task of the soil softener is minimal technological soil compaction, sowing and pre-sowing by implementing the method is to perform cultivation operations. Deep emollient aggregate-having different mechanical composition, resistance 0.04-0.11. Mpa and relative humidity all mountains, foothills and plains of the Republic on lands with $17-21 \%$ can be used in climatic zones. Studies show that inter-row and intervine cultivation of soils in vineyards is the most is one of the important processes. Soil through cultivation softening, prevention of moisture loss in the soil, its ventilation, surfacelayer prevention of erosion, its structural stay and weeds is one of the important operations performed for cleaning.
\end{abstract}

\section{Keywords}

Combined, aggregate, emollient-semi-emollient, emollient, plant residues

The analysis of agrotechnical results in inter-row cultivation of vineyards shows that the best value of the degree of grinding is observed in the optimal fractions of $10-25 \mathrm{~mm}(5.6 \%)$ and $25-50 \mathrm{~mm}(74.5 \%)$, only $80.1 \%$ of the total movement was obtained by increasing the speed by $2.32 \mathrm{~m} / \mathrm{s}$. The width of the cracks opened at the speed of movement (front, side right and side left) and the general depth of cultivation, complete cutting of plant residues and weeds, high coverage of the upper layer (97.5\% quality) were reflected in inter-row cultivation of vineyards. In order to determine the operational and technological parameters of the softener-semiconductor, chronometric observations were carried out between the rows of vineyards by the standard method and the calculations showed their high results.

\section{Introduction}

An important problem in the development of mechanization of land cultivation in the mountainous and lowland conditions of the republic is the implementation of modern technological methods to prevent deep solidification of the soil, as well as the prevention of soil erosion by performing semi-tillage, cropping, drainage and chipping operations [1].

One of the most important issues is to reconsider the agro-technical, operational, technological and energy assessment of agricultural machinery in order to substantiate the agro-technical requirements [2].

Combined machines and aggregates belong to the group of machines that lead to high-quality technological process, increase productivity (up to 10\%) and labor productivity (2-4 times). However, the combined machines belong to the 
combination of a number of operations in the basic and pre-sowing cultivation of the soil, which is widely used in the world practice, and technical means in the minimal cultivation of the soil. It also includes a combination of combined disc, padding, chisel and other machines used in surface cultivation of the soil. The application of minimal cultivation in the cultivation of agricultural crops reduces the intensity of the impact of machines and tools on the soil, leads to a more effective solution to the problem of maintaining soil fertility, increases productivity and production efficiency [3, 4].

\section{Analysis and Discussion}

The main reason and result of the creation of combined tillage machines using various plasticizers and levelers is mainly to fulfill important agrotechnical requirements for leveling the field surface to maintain productive moisture in areas with low humidity. It is known that plowing completely protects the arable layer, destroying the uneven structure of the soil during plowing, which greatly limits the role of the accumulator for retaining moisture in the soil $[5,6]$.

Taking into account modern requirements in relation to complexes of anti-erosion equipment, it is necessary to note the following disadvantages of currently produced machines for processing anti-erosion soils:

- $\quad$ low allowable speed of movement, which leads to low productivity;

- $\quad$ very large metal content compared to;

- $\quad$ lack of justification for the maximum width of the machine;

- $\quad$ relatively low versatility and uniformity;

- relatively high tensile strength.

The following agrotechnical requirements are at the heart of the design of tillage tools and machines used in presowing soil cultivation in erosion-prone areas:

- $\quad$ protecting the soil from wind erosion, preventing moisture evaporation, as well as maintaining the maximum number of roots and plant residues to prevent young plants from falling asleep with sand and fine soil particles;

- maintain the roughness of the upper soil layer, prevent an increase in erosion-hazardous fractions of less than $1 \mathrm{~mm}$ in $5 \mathrm{~cm}$ of the soil layer after the movement of the machine;

- $\quad$ combination of the maximum number of operations in one move of the tractor;

- $\quad$ reduction of labor costs and money per unit of production.

Minimization in soil cultivation is the development of intensive technologies and the creation of combined plasticizers, semi-rollers, chisel cultivators and leveling machines while maintaining moisture and roughness of the soil in accordance with agrotechnical requirements when leveling the field surface. However, minimizing tillage is intended to prevent the erosion process and prevent re-solidification of the soil by tractor units.

Therefore, in more combined aggregates, it is advisable to use the half-run as a free operation, since it is very promising as a practical agricultural method. Examples of such combined units are half-rolled, half-rolled, damping, softening, etc. can be shown $[5,6,7,8]$.

The analysis of combined tillage with intensive technology in various variants justifies the use of 4 types of internal organs in specific production conditions and soil and climatic conditions. To create mulch on the upper surface of the cultivated land, deep softening paws, reversible knives, large capacity pads and combers are provided.

A two-dimensional modular semiconductor plasticizer is developed according to two technological schemes with the placement of these 4 types of bodies in a combined frame in a single frame.

In an improved version of the modular hemisphere of the softener, the legs (5) of the softener are placed independently on the cross beam (1) of the frame independently of each other and allow you to adjust the depth and place the front and rear two-dimensional hemispheres at different distances from each other on the transverse base.

The heel of the large-capacity cushion (9) is attached to the rear wall of the central axis with the help of a perforated fork. The tip of its wings is similarly attached to the fork of a two-sided hemisphere (7.8) located at the back of the frame (1). The rope combing of plant remains, in turn, is connected in a triangular shape with the front and rear hemispheres. The two edge rear softening claws (5) are located in the middle of the frame (1) and soften the soil to a depth of $25-30 \mathrm{~cm}$. Lateral double-sided slits (7.8) make cracks in the tire tracks to a depth of 35-40 cm. The rope comb (10) (depending on the connection with the fork to the semicircle) is mounted on the upper part of the cushion (9), through which the soil is cultivated to a depth of $20-25 \mathrm{~cm}$, and the cable comb is cultivated to a depth of $15-20 \mathrm{~cm}$. At the same time, with additional softening, it retains the accumulated plant residues as mulch and provides moisture to the soil surface.

Cultivation of soils with different mechanical composition, resistance (0.4-1.1) of 10-1 MPa with new construction softener-semi-permanent and provides the following: 


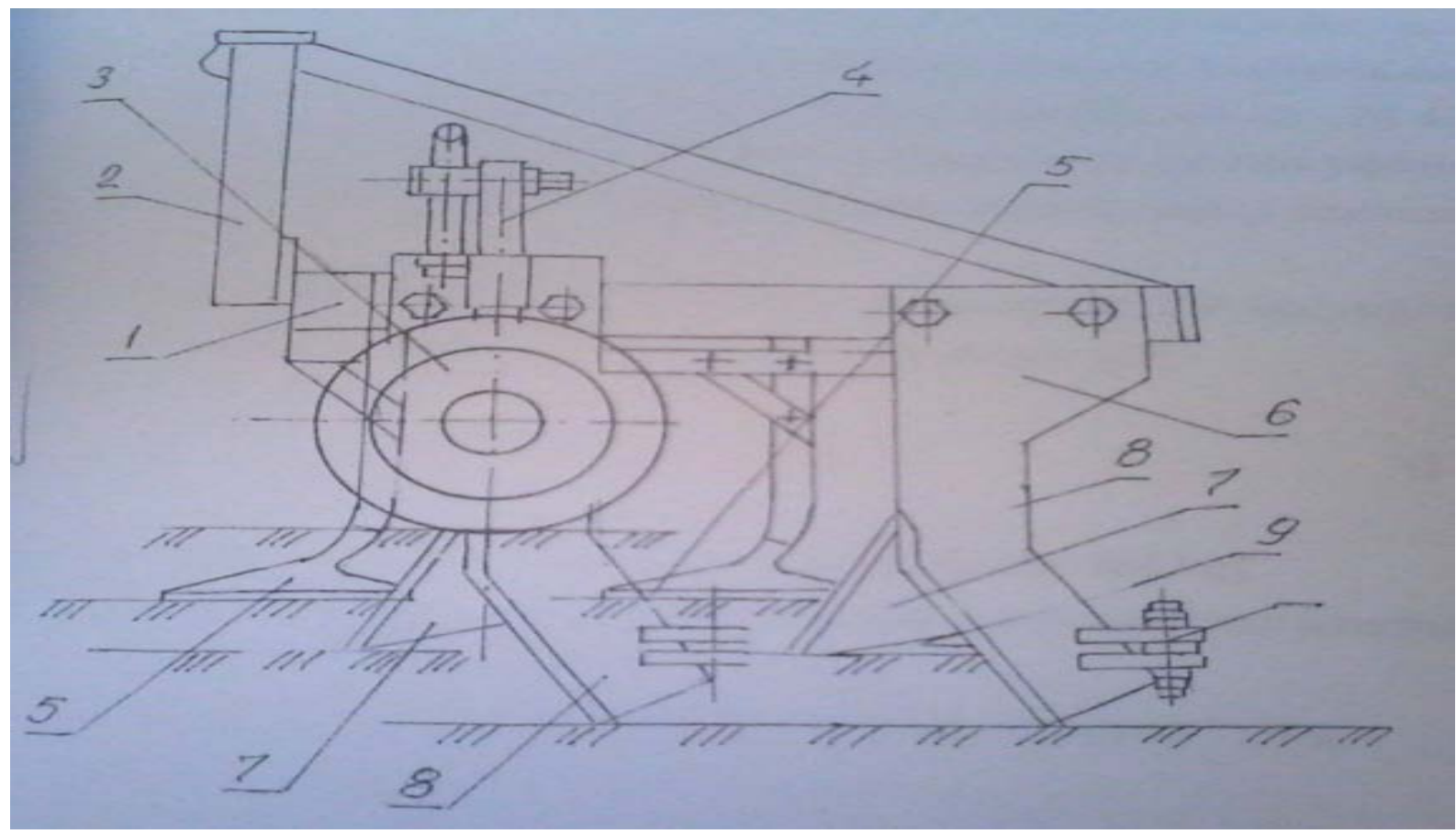

1-frame; 2-trailers; 3-support and adjusting wheel; 4-regulating device; 5-softening paw; 6-and-a-half support;

7-front upper hemisphere; 8-posterior hemisphere of the lower tier; Flat cutter 9-large-angle flat cutter;10 rope combing

Figure 1. Technological diagram of a modular semiconductor plasticizer.

- $\quad 4$ softening claws can be adjusted autonomously on the frame, both in width and depth of soil;

- 3 two-sided hemispheres are placed in a triangular shape on the frame, one on the central axis of symmetry in front, two on the back;

- $\quad$ Toothed trowels, which can be fastened with a large bending pad and a cable comb on its upper part.

The development trend of innovative technologies in the countries of the world is directed towards the development of a new generation of machines and combined tillage units, such as pillows, mulching machines, rollers, semi-rollers and milling machines $[9,10,11]$.

Combined machines combine the cultivation of the top layer of soil and the deep softening of the bottom layers to a depth of $40-45 \mathrm{~cm}$ using chisels and semi-chisels. It is expedient to apply it in more combined aggregates, as it is very promising as a practical agro-method as a free operation. Examples of these combined aggregates are semi-rolling, semi-rolling, cushioning, softening and so on can be shown [12, 13, 14, 15].

Prior to the test processes in the Kovshan area, the conditions and condition of the field - the relief of the field, its littering with plant remains, the slope of the field, the degree of stonyness, soil hardness, special resistance and moisture were studied [16,17].

In order to determine the agro-technical parameters of the softener-semi-escape, the research work was carried out on the cultivation of the soil in the test areas under the bush, as well as on the cultivation of rows of vineyards planted in the $3 \times 1.5 \mathrm{~m}$ scheme.

Agrotechnical assessment and comparative analysis of the obtained results are given in the table. The results of the analysis show that the best value of the degree of soil compaction in the optimal fractions is $10-25 \mathrm{~mm}$ and $25-50 \mathrm{~mm}$ $(74.5+5.6)=80.1 \%$ unit speed $2.32 \mathrm{~m} / \mathrm{s}$ is obtained by raising the san.

By analogy, the more stable cultivation depth is obtained from the average value of the mathematical plow, which is $1.0 \mathrm{~cm}$, the coefficient of variation is $5.81 \%$, the error of the test is 0 , at an average speed of $2.32 \mathrm{~m} / \mathrm{s} \mathrm{at} 12.1 \mathrm{~cm} .2 \mathrm{~cm}$ and the accuracy of the test was $1.65 \%$.

The rate of complete cutting of plant residues and weeds at all speeds, the high level of topsoil cover (mulching quality) was $97.5 \%$, and a very small percentage of plant residues remained on the top layer of the cultivated background.

The speed of the unit at $2.32 \mathrm{~m} / \mathrm{s}$, the depth of the top, front right and left unfilled cracks ensure the quality of the half-escape process. It should also be noted that the application of soil on the working bodies at a high speed of the unit was $2.32 \mathrm{~m} / \mathrm{s}$ on the cushion-deep softener, the thickness of the soil was 1.5 and $2.5 \mathrm{~mm}$ versus $1.0 \mathrm{~mm}$, which is very small. This confirms that self-cleaning takes place with increasing speed. A similar cleaning is observed on the side supports of the blades of the 2-tier hemisphere, the cost of which is $1.0 \mathrm{~mm}$. 
Table 1. Quality indicators of softener-semiconductor operation in the area under Kovshan

\begin{tabular}{|c|c|c|c|c|c|c|}
\hline & \multirow{2}{*}{$\begin{array}{l}\text { Quality indicator of technological } \\
\text { process }\end{array}$} & \multicolumn{5}{|c|}{ Results of mathematical calculations } \\
\hline & & $\begin{array}{l}\text { Average } \\
\text { score, M }\end{array}$ & $\begin{array}{l}\text { Mean square } \\
\text { inclinatio } \pm \sigma\end{array}$ & $\begin{array}{c}\text { Coefficient of } \\
\text { variation, } v, \%\end{array}$ & $\begin{array}{c}\text { Test error } \\
\quad \pm \mathrm{m}\end{array}$ & $\begin{array}{c}\text { Test accuracy, } \\
\text { n, } \%\end{array}$ \\
\hline \multirow{4}{*}{1} & Growing depth: & & & & & \\
\hline & - softening windows & 12.1 & 1.0 & 8.26 & 0.20 & 1.65 \\
\hline & - mild emollient & 17.2 & 1.0 & 5.81 & 0.20 & 1.16 \\
\hline & - two-levelsemiautomatic device & 30.5 & 1.0 & 3.28 & 0.20 & 0.65 \\
\hline \multirow{4}{*}{2} & The width of the crack, $\mathrm{cm}$ : & & & & & \\
\hline & - front halfway & 5.5 & 1.25 & 22.72 & 0.25 & 4.54 \\
\hline & - side right & 5.5 & 1.25 & 22.72 & 0.25 & 4.54 \\
\hline & - side left & 5.5 & 1.25 & 22.72 & 0.25 & 4.54 \\
\hline \multirow{4}{*}{3} & Depth of soil to a pan, cm: & & & & & \\
\hline & - front slit & 10.5 & 3.5 & 33.33 & 0.70 & 6.66 \\
\hline & - side right slit & 7.5 & 2.0 & 26.66 & 0.40 & 5.33 \\
\hline & - side left slit & 7.5 & 2.0 & 26.66 & 0.40 & 4.33 \\
\hline \multirow{6}{*}{4} & Degree of soil fractionation: & & & & & \\
\hline & -less than $10 \mathrm{~mm}$ & 2.7 & - & - & - & - \\
\hline & $-10-25 \mathrm{~mm}$ & 5.6 & - & - & - & - \\
\hline & $-25-50 \mathrm{~mm}$ & 74.5 & - & - & - & - \\
\hline & $-50-100 \mathrm{~mm}$ & 13.8 & - & - & - & - \\
\hline & -more than $100 \mathrm{~mm}$ & 3.4 & - & - & - & - \\
\hline 5 & $\begin{array}{c}\text { Degree of degradation of plant residues } \\
\text { and weeds, \% }\end{array}$ & 100 & - & - & - & - \\
\hline 6 & Burial rate of plant remains, \% & 97.5 & - & - & - & - \\
\hline \multirow{4}{*}{7} & $\begin{array}{l}\text { Thickness of soil adhesion to working } \\
\text { bodies, mm: }\end{array}$ & & & & & \\
\hline & - softening paws & 0.0 & 0.0 & 0.0 & 0.0 & 0.0 \\
\hline & - cushioning-deep emollient & 1.0 & 0.25 & 25.0 & 0.05 & 5.0 \\
\hline & - 2-tier half-escape & 1.0 & 0.25 & 25.0 & 0.05 & 5.0 \\
\hline
\end{tabular}

\section{Reference}

[1] Agabeyli, T. A., Zeynalov, S. G. (2003). Combined tillage machine with spherical semi-disc. Azerbaijan Agrarian Science, 2003, No. 1-3, pp. 153-154.

[2] Huseynov, F. Q. (2006). Cultivation of soil against mountain erosion on mountain slopes. Azerbaijan Agrarian Science, 2006, No. 5-6, pp. 227-228.

[3] Agabeyli, T. A., Huseynov, F. Q. (2008). Research of multifunctional softener-semicon-ductor. Azerbaijan Agrarian Science, 2008, No. 4-5, pp. 111-113.

[4] Guluyev, H. Y., Pashayev, V. A., and Isgandarov, E. B. (1999). Application of dynamics of universal tillage machine for viticulture. Azerbaijan Agrarian Science, 1999, No. 3.

[5] Kerimov, Y. G. (2008). Efficiency of moldboard-free tillage on slope lands of Azerbaijan. Agrarian Science of Azerbaijan, 2008, No. 2, art. 32-33.

[6] Panov, I. M., Kiryukhin, V. G., and Sakun, V. A. (1986). Promising directions of development of machines for basic tillage. Exp. Inf. TSNIITEI Traktorselkhozmash, M., 1986, No. 29, Art. 27. 
[7] Pannikov, V. D. (1978). On the development of research on soil conservation agriculture. Bulletin of agricultural science, 1978, No. 2, Art. 29-39.

[8] Tyrnov, Y. A., Zazulya, Y. N., Gnilomedov, V. G., Afonin, E. A., Sazonov, D. S., and Yerzamaev, V. G. (2007). Improvement of technologies and technical means of soil cultivation. Technics in agriculture, 2007, No. 6, Art. 34-38.

[9] Akhunov, T. I., Gafarov, A. A., and Safarov, M. S. (2008). Power characteristic of the working body of the combined tillage machine. Mechanization and electrification of agriculture, 2008, No. 3, art. 16-17.

[10] Kuznetsov, A. V. (2008). On the introduction of resource-saving agricultural technologies. Technology and equipment for the village, 2008, No. 3(129), art. 36-37.

[11] Spirin, A. P., Izmailov, A. Y., Sizov, O. A., and Izvekov, A. S. (2008). Minimal mulch tillage. Technician in agriculture, 2008, No. 1 , art. 27-32.

[12] Agabeyli, T. A. (2010). Research of kinematics and dynamics of a spherical half-disk of a harrow. Messages from the Academy of Agricultural Sciences of Georgia, 2010, No. 28, pp. 346-350.

[13] Alakbarov, H. T., H. Z. Aliyev, İbrahimova, M.Sh., Allahverdiyeva, K.F., and Babayeva, E. X. (2018). Task and application area of soil cultivator deeply softening aggregate. Ministry of Agriculture of the Republic of Azerbaijan, Azerbaijan State Agrarian University “Agro-Mechanics” Research Institute, Mechanization and electrification of agricultural production in the Republic of Azerbaijan- “Actual problems of scientific and technical progress in agricultural production” dedicated to the 100th anniversary of the Azerbaijan Democratic Republic Materials of the scientific-practical conference on the topic, XXI volume, Baku, 2018, pp. 90-95.

[14] Zhukova, O. (2010). Modern technologies and equipment for pre-sowing soil cultivation. Machinery and Equipment for the Village, 2010, No. 12, pp. 13-15.

[15] Dyomshin, S. A., Vladimirov, E. A. (2010). Calculation of the optimum working width of the machine for soil cultivation and sowing. Machinery and Equipment for the Village, 2010, No. 5, pp. 3-6.

[16] Kiselev, S. N. (2010). Main tillage with rotary diggers. J. Technics and Equipment for the Village, 2010, no. 9, pp. $42-44$.

[17] Nagiyev, E. M, Mammadov, M. F., Yagubov, K. H., Gurbanov, K. H., Mammadov, I. O., Mammadov, T. M., and Hasanova, S. H. (2018). Results of the investigation of the combined plough. Ministry of Agriculture of the Republic of Azerbaijan, Azerbaijan State Agrarian University “Agromechanics” Research Institute, Mechanization and Electrification of Agricultural Production in the Republic of Azerbaijan-Scientific conference on "Actual problems of scientific and technical progress in agricultural production" dedicated to the 100th anniversary-Materials of the practical conference, 2018, XXI volume, Baku, pp. 59-64. 